\title{
Formation of sports clusters of the territory, considering the concept of SROI
}

\author{
Svetlana Pyankova*, and Dmitriy Arkalov \\ Ural State University of Economics, Yekaterinburg, Russia
}

\begin{abstract}
The article considers a cluster approach to the development of sports infrastructure in the concept of sustainable development of territories. Analysis of foreign and Russian experience shows a high potential for the concentration of the system of organizations in a certain territory, as a mechanism for the effective and rational use of the resource potential of the region. The sports cluster has its own characteristics in the construction and organization of the functioning process. From the standpoint of social return on investment (SROI) in sports, it is necessary to provide convenience for users of as many categories as possible, ranging from healthy lifestyle enthusiasts to professional athletes. Taking these features into account makes it possible to ensure the maximum load of the sports infrastructure, create additional social benefits and help to attract extra budgetary funding sources. On the other hand, the divergent interests of various categories of users of the sports infrastructure can serve as an obstacle to uniting amateurs and professionals on the same territory.
\end{abstract}

\section{Introduction}

Providing the population with sports facilities is one of the components of the potential for the development of sports in a municipality or subject. Today, 29 types of sports facilities are classified in Russia [1]. The development of the sports infrastructure is planned in various programs for the development of the sports sector. But when choosing an object for construction, it is important to rely on the population's need for a particular sports facility, the popularity of the sport (the demand for the sport), the subject's ability to maintain the object planned for construction, as well as the characteristics of the territory. Concentration on a certain territory of a group of sports institutions and organizations, which are functionally interconnected and dependent on each other, while implementing the general process and achieving a common goal is called a sports cluster [2a]. The sports cluster model refers to the geographic concentration of interrelated organizations with a particular interest in sports or related sports [3]. Foreign researchers note that the issues of sports management should be analyzed in the context of the entire system of joint creation of values in the sports sphere - at the meso-level, and not from the point of view of individual elements (individuals, institutions, organizations) [4]. According to the research results of S.B. Boldyreva and her colleagues, an economic cluster is formed if the values of localization indicators for the use of certain types of resources in the region exceed the

\footnotetext{
*Corresponding author: silen_06@list.ru
} 
national average - this is indirect evidence, since it is such a system that effectively and rationally uses the resource potential of the region [5]. In the direction of the development of high-performance sports (Olympic sports) and related professional sports, Russian researchers and specialists are studying and testing the transition to the cluster organization of the sports training process. The practical application of the cluster approach makes it possible to overcome economic, social and organizational barriers for cluster members with different types and forms of organization, due to their implementation of the general concept and developed strategy. This allows you to remove information and interdepartmental barriers [6a, 7a]. A.S. Voronov in his research notes that clusters can be an effective tool for sustainable regional development [8].

\section{Materials and methods}

In the practice of sports development, a cluster approach is considered and applied to the construction of a sports infrastructure. When analyzing research in the direction of the cluster approach, some scientists note that it is one of the methods for solving the problem of providing citizens with the opportunity to engage in physical culture and sports, since a sports cluster unites various institutions and services, training and entertainment events [2b], and development in this direction corresponds to the concept of competitive strategy and international competitiveness in the field of economic competition by M. Porter [9]. Moreover, the more participants in a sports cluster, the more complex the structure, resulting in difficulties in interaction [10], despite the fact that many barriers are removed. The results of A. Gerke's research showed the complexity and varied nature of interorganizational relationships in the clusters of the sports industry [11].

In view of the fact that sport in Russia belongs to the state sector of the economy and is $90 \%$ financed from budgetary funds [12], the construction of a commercial sports cluster, according to the authors, is impossible at this point in time. Therefore, the organization of a sports cluster, first of all, must be considered as a socio-economic project, which should be based on the concept of SROI (Social return on investment). SROI was first established by the Roberts Entrepreneurship Development Foundation (REDF) in San Francisco [13]. The SROI framework is a cost-benefit approach to measurement; analysis, social accounting and social auditing that reflect social value; translating social goals into financial and nonfinancial assets. SROI measures the value of benefits relative to the cost of achieving them. One of the advantages of this method is the ratio of the net present value of the benefits to the net present value of the investment. SROI is an approach through which it is possible to measure and take into account value in a broad sense. It aims to reduce social inequalities and increase the personal well-being of people by taking into account social, environmental and economic costs and benefits. [14,15]. In the author's interpretation, in accordance with the SROI concept, social return is the formation of new intangible social values in society or the strengthening of existing ones based on the creation of material goods for general use. According to paragraph 1 of Art. 7 of the Constitution of Russia: The Russian Federation is a social state, the policy of which is aimed at creating conditions that ensure a dignified life and free human development [16]. The construction of a sports cluster as a socio-economic project based on the use of SROI fits into the concept of initiative budgeting [17]. The SROI approach was modified by A.V. Litvin, A.N. Kazakov, and L. Esipovich. Scientists have refined the calculation and analytical tools and supplemented the theoretical provisions of the methodology for calculating the indicators of social efficiency of the use of state and non-state resources allocated to the field of sports. The modified method allows the development of socially oriented projects from the standpoint of the obtained and predicted material and non-material results [18].

Sports clusters can be divided into the following areas: 
1. Sports and tourism;

2. Student;

3. High performance sports oriented.

Sports and tourism clusters are considered in the works of A.V. Mamaeva, M.A. Semenov [19], V.S. Pilyutkevich [20] and others. Student sports clusters are based primarily on higher educational institutions [7b, 21, 22]. It should be noted that the most progressive system of the cluster approach to student sports is built in the United States. The American model places a lot of emphasis on college sports. The American approach allows athletes, starting from school, to purposefully move into professional and Olympic sports. Cluster interaction between different levels of educational institutions is clearly expressed in the support of athletes: the National Federation of State High School Associations (NFHS) oversees school competitions at the national level and unites 19,500 educational institutions, and the National Collegiate Athletic Association (NCAA) oversees student competitions, uniting 1,280 colleges and universities [23].

Modeling and building sports clusters focused on elite sports is very specific. The focus on sports results does not always allow the formation and coverage of several multidirectional sports, since the higher the level of athletes in a particular sport, the more individual approach to training. Accordingly, the end product of the functioning of such a system is high-class athletes for the national sports team, which is the opposite of the physical culture and health work required for the majority of citizens. T.V. Fendel, D.A. Zubkov, and V.A. Litovchenko are engaged in the formation of sports clusters with a focus on sports training [6b].

\section{Results and discussion}

From the standpoint of the SROI concept, we will model the social non-material results of the functioning of the considered sports clusters.

The result of the work of the sports and tourist cluster can be the creation of a recreational zone, both within the city and outside it. With this approach, the cluster can combine both sports and recreational work with athletes during summer camps or training camps (if the program does not require specialized facilities and equipment), as well as active recreation for citizens. At the same time, the program of events should also include entertainment within the framework of the concept of a healthy lifestyle. A choice in favour of a healthy lifestyle as an alternative to the entertainment industry and passive recreation can serve as a social return, which will have a positive effect on the emotional and physical state of citizens. For a sports and tourism cluster, the primary stakeholders should be regional (municipal) authorities and citizens.

Student sports clusters, when built according to the American-style model, can serve as a powerful social lift for those who want and have a predisposition to sports. Today, student sports in Russia are not as well developed as in the United States. With this approach, a social effect can be a system in which it will be possible to build the training process and training camps without interrupting for a long time from the educational process [24, 25]. This, in turn, will allow students not to drop out of the educational process and to be more socially adapted to work outside the field of sports after the end of their sports career. The main stakeholders in student sports clusters should be the Ministry of Education and Science of the Russian Federation, universities, and students.

Sports clusters aimed at sports training can be difficult to combine with recreational work and active recreation for citizens due to the tight schedule of the training process, as well as expensive and specialized equipment that is not needed by lovers of a healthy lifestyle. A trained athlete can serve as a social effect, as a role model and inspiration for young athletes and their parents. This approach forms the most specific social value, 
expressed in the formation of an "idol" and "opinion leader", which is currently expressed in the active social life of some athletes. The interested parties in such sports clusters will primarily be the Ministry of Sports of the Russian Federation, regional ministries of sports, and athletes.

\section{Conclusions}

When choosing a direction for the formation of a sports cluster: student, sports and tourism, or a cluster focused on sports training, in the first place it is necessary to determine the goal and valuable end product that must be formed and released into the external environment as a result of the cluster functioning. The use of SROI in the formation of a cluster will allow a harmonious combination of material and non-material (social) benefits that will be achieved. With the help of SROI it will be possible to predict and select the desired social effect. It is worth noting that the achievement of the selected effect with systematic work can take from 3 to 10 years.

\section{References}

1. Order of the Ministry of Sports of the Russian Federation of February 25, 2016 No. 172

2. V. V. Ananishnev, V. V. Korepova, Clusters. Research and development, 2(2), 35 (2016)

3. A. Gerke, M. Desbordes, G. Dickson, European Sport Management Quarterly, 15(3), 343 (2015)

4. A. Gerke, M. Desbordes, G. Dickson, 23rd European Associatio for Sport Management (EASM) Conference At: Dublin, Ireland (2015)

5. S. B. Boldyreva, A. K. Alimov, R. T. Adilchaev, D. V. Idzhilova, N. E. Chadlaeva, International Journal of Management, 11(11), 749 (2020)

6. V.A. Litovchenko, D.A. Zubkov, T.V. Fendel, Theory and practice of physical culture, 6, 98 (2020)

7. V.A. Rodionov, M.A. Rodionova, V.V. Apokin, Theory and practice of physical culture, 12, 100 (2012)

8. A.S. Voronov, Intellect. Innovation. Investments, 9, 27 (2018)

9. V. V. Ananishnev, R. R. Khafizov, Clusters. Research and development, 2(2), 22 (2016)

10. R. A. Wolfe, K. E. Weick, J. M. Usher, Journal of Management Inquiry, 14(2), 182 (2015)

11. A. Gerke, Conference: Annual conference of European Acacemy of Management (EURAM) At: Warsow, Poland, 3, (2015)

12. Statistical report No. 1-FC for 2020, https://minsport.gov.ru/

13. J. Emerson, Making Waves, 11(2), 10 (2000)

14. G. Blokdyk, Social Return On Investment A Complete Guide - 2021 Edition, 5STARCooks, 223 (2020)

15. V. Then, C Schober, O Rauscher, K. Kehl, Social Return on Investment Analysis: Measuring the Impact of Social Investment, 406 (2018)

16. The Constitution of the Russian Federation, http://www.constitution.ru/ 
17. I.S. Antsyferova, Higher education today, 11, 48 (2017)

18. A. V. Litvin, A. N. Kazakov, L. Esipovich, Teoriya i pracktika fizicheskoy kultury, 1, 40 (2017)

19. A.V. Mamaeva, M.A. Semenov, Bulletin of the Irkutsk State Technical University, 10 (57), 226 (2011)

20. V. S. Pilyutkevich, Modern management: problems and prospects: Collection of articles: in two parts, St. Petersburg, April 07-08, 376 (2016)

21. D.I. Surnin, N.A. Usachev, Bulletin of the Tomsk State University, 444, 206 (2019)

22. V. I. Grigoriev, A. V. Taymazov, Yu. K. Shubin, Scientific notes of the University. PF Lesgaft, 3(97), 47 (2013)

23. S.G. Pyankova, D.P. Arkalov, Regional problems of economic transformation, 1(123), $74(2021)$

24. N. A. Zinoviev, Health is the basis of human potential: problems and ways to solve them, 5(1), 231 (2010)

25. N.L. Ilyina, E.E. Khvatskaya, R.A. Berezovskaya, Uchenye zapiski universitet im. PF Lesgaft, 11(153), 325 (2017) 